\title{
Temperature accelerated life test on commercial concentrator III-V triple-junction solar cells and reliability analysis as a function of the operating temperature
}

\author{
P. Espinet-González ${ }^{1}{ }^{*}$, C. Algora ${ }^{1}$, N. Núñez ${ }^{1,2}$, V. Orlando ${ }^{1}$, M. Vázquez ${ }^{1,2}$, J. Bautista $^{1}$ and \\ K. Araki ${ }^{3}$ \\ 1 Instituto de Energía Solar - Universidad Politécnica de Madrid, ETSI de Telecomunicación, Avda. Complutense 30, 28040, \\ Madrid, Spain \\ 2 EUIT de Telecomunicación, Universidad Politécnica de Madrid, Madrid, 28031, Spain \\ 3 Daido Steel Co., Minami, Nagoya, Japan
}

\begin{abstract}
A temperature accelerated life test on commercial concentrator lattice-matched $\mathrm{GaInP} / \mathrm{GaInAs} / \mathrm{Ge}$ triple-junction solar cells has been carried out. The acceleration of the aging has been accomplished by subjecting the solar cells at temperatures markedly higher than the nominal working temperature inside a concentrator, and the nominal photo-current condition $(820 \mathrm{X})$ has been emulated by injecting current in darkness. Three tests at different temperatures have been carried out. The failure distributions across the three test temperatures have been fitted to an Arrhenius-Weibull model. An Arrhenius activation energy of $1.59 \mathrm{eV}$ was determined from the fit. The reliability functions and parameters of these solar cells at two nominal working conditions $\left(80\right.$ and $100^{\circ} \mathrm{C}$ ) have been obtained. In both cases, the instantaneous failure rate function monotonically increases, that is, the failures are of the wear-out kind. We have also observed that the reliability data are very sensitive to the nominal temperature condition. In fact, at a nominal working condition of $820 \mathrm{X}$ and $80{ }^{\circ} \mathrm{C}$, assuming that the concentration module works $5 \mathrm{~h}$ per day, the warranty time obtained for a failure population of $5 \%$ has been 113 years. However, for a nominal working condition of $820 \mathrm{X}$ and $100{ }^{\circ} \mathrm{C}$, the warranty time obtained for a failure population of $5 \%$ has been 7 years. Therefore, in order to offer a long-term warranty, the working temperature could be a key factor in the design of the concentration photovoltaic systems. Copyright @ 2014 John Wiley \& Sons, Ltd.
\end{abstract}

\section{KEYWORDS}

accelerated life test; ALT; reliability; concentration; multijunction; solar cells; III-V; CPV; photovoltaics

*Correspondence

P. Espinet-González, Instituto de Energía Solar - Universidad Politécnica de Madrid, ETSI de Telecomunicación, Avda. Complutense

30, 28040, Madrid, Spain.

E-mail: pespinet@ies-def.upm.es

Received 9 April 2013; Revised 20 November 2013; Accepted 27 November 2013

\section{INTRODUCTION}

According to several studies [1-5], concentration photovoltaic systems (CPV) seem to be one of the most promising ways to generate electricity at competitive prices for terrestrial applications. Besides, in order to be costcompetitive, a high reliability similar to that of silicon modules is essential. Aware of this problem, the CPV community has developed a standard (IEC-62108:2007) for qualifying CPV modules and assemblies [6], and a standard for qualifying solar cells is being developed (IEC62787). Qualification tests are designed to specify the minimum requirements that the item under test should sat- isfy. However, they are not a good indicator of the item's lifetime because their duration is not long enough to cause wear-out degradation. Therefore, in order to estimate the failures/year, the projected returns and warranty costs of high concentration solar cells, it is crucial to carry out reliability tests. Reliability tests, also known as life tests, are designed to evaluate failures and to quantify them [7]. Therefore, reliability tests go much beyond qualification.

Silicon modules are reliable systems, which perform very well in the field with less than $1 \%$ power degradation/year for more than 20 years [8]. However, up to now, there is not enough accumulated experience to evaluate the reliability of concentrator modules, including multi- 
junction solar cells, because they have not been in the field long enough. Therefore, accelerated life tests (ALT) are required to provide reliability information in a moderate period of time (weeks or months). In this study, we describe the approach, design, set-up, progress, and reliability data obtained from the temperature ALT, which has been carried out on 45 lattice-matched GaInP/GaInAs/Ge triple-junction solar cells. The methodology followed in ALT together with some preliminary results have been presented in [9]. In this paper, we present for the first time (to the best of our knowledge) the complete reliability analysis including the determination of the reliability functions and parameters obtained for concentrator multijunction solar cells.

\section{ACCELERATED LIFE TEST APPROACH}

The purpose of accelerated life testing is to find out how and when failures occur in the device under test more quickly than under normal operating conditions. For this purpose, one of the parameters of the device under test is stressed leaving the rest of the parameters at the nominal operation condition. The high levels of stress in one of the parameters force failures by accelerating the effects of natural aging. Some important assumptions are considered in the ALT as follows:

(i) The failure-causing process at high stress is the same as at the nominal stress.

(ii) A physical/chemical process causes a change in the device under test, and this change progresses over time to eventually cause failure.

(iii) The applied stress accelerates reaction rates, and this acceleration can be described by a model that is accurate over the range of testing.

Once all the devices under test have failed, the analysis of ALT data consists of the following:

1. Finding a life distribution that describes the distribution of failures at different stress levels.

2. Finding a life-stress model that quantifies the manner in which the life distribution changes across different stress levels through an acceleration factor. In order to obtain a reliable value of the acceleration factor, at least three tests at three different stress levels are necessary.

3. Combining the life distribution and the life-stress model to evaluate the complete model at nominal working conditions.

Once we have a physically reasonable statistical model that relates the lifetime to the level of stress through an acceleration factor, the life data from the ALT can be used to extrapolate reliability information at nominal working conditions. Therefore, the same functions and parameters that could be obtained from standard life data analysis (non-accelerated) can also be achieved from an ALT.

\section{ACCELERATED LIFE TEST UNDERTAKEN}

In this work, an ALT has been carried out on commercial lattice-matched GaInP/GaInAs/Ge triple-junction solar cells with an active area of $0.49 \mathrm{~cm}^{2}$. The methodology followed in the ALT is an adaptation from the procedure already carried out satisfactorily on GaAs concentrator solar cells [10]. The parameter used to accelerate the aging of the solar cells has been the temperature. As it has been pointed above in Section 2, at least three tests at different temperatures have been necessary in order to achieve a reasonable fitting to the life-stress model used (later described in Section 6.1). Regarding the working conditions, they have been emulated by injecting in darkness the equivalent current that the solar cell would photo-generate in illumination at the nominal concentration level $(820 \mathrm{X})$. In order to register the time interval in which each solar cell has failed, the dark I-V curve of the solar cells has been periodically monitored during the tests.

The steps followed in the ALT have been classified into four stages as shown in Figure 1: (1) design of the test; (2) progress of the test; (3) reliability data analysis; and (4) failure analysis. In this paper, we describe the steps followed in stages (1) and (2) and the reliability data analysis carried out in part (3). The failure analysis is under development, and it will be presented in a further study.

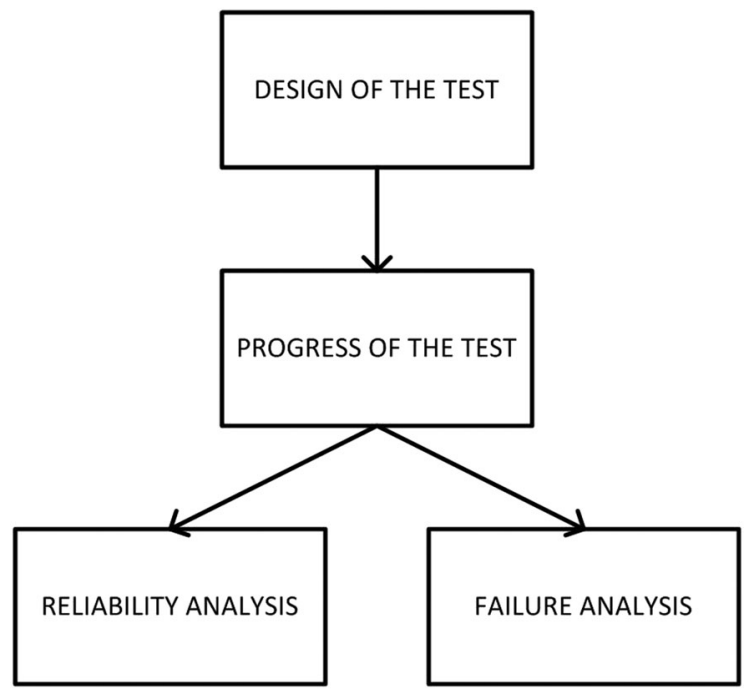

Figure 1. Sketch of the stages of the accelerated life test. In this paper, a detailed description of all the parts is presented, except for the failure analysis which will be treated in a subsequent study.

\section{DESIGN OF THE TEST}

The following information needs to be determined in order to start with the experiment: 


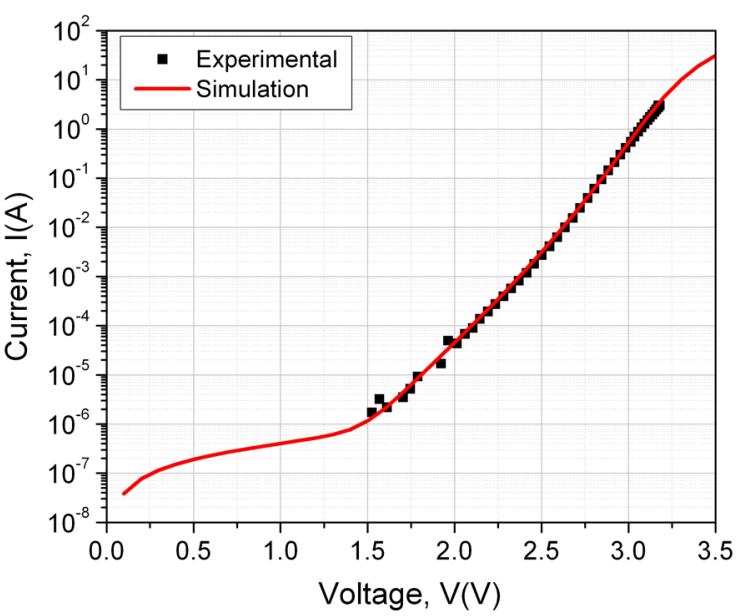

Figure 2. Experimental measurements and simulation results by using the 3D distributed model described in [11] of the dark I-V curve of a triple-junction solar cells used in the ALT.

(i) Nominal working conditions under concentration.

These particular solar cells are expected to work inside an optical concentrator at $820 \mathrm{X}$ and $80{ }^{\circ} \mathrm{C}$.

(ii) Current that has to be injected in darkness to emulate working conditions.

With this purpose, simulations with our 3D distributed model for triple-junction solar cells described in [11] have been carried out. In order to have reliable simulations, the parameters that feed the model have been obtained by fitting the experimental dark I-V curve and the illuminated I-V curve under different irradiance levels and spectral conditions. The excellent results of the fitting are shown in Figures 2 and 3.

Once we had a reliable model for reproducing the performance of these commercial triple-junction solar cells, they were simulated under a uniform irradiance of $820 \mathrm{X}$. In Figure 4, false color maps of the photo-generated current density through the different pn junctions when the solar cell operates at $820 \mathrm{X}$ at the maximum power point are depicted. In the active area, the current density is positive and around $11.5 \mathrm{~A} / \mathrm{cm}^{2}$. Therefore, the tunnel junctions are working in the first quadrant. However, beneath the busbar and fingers, the current density is negative (gray scale) because the recombination diodes are draining some of the photo-generated current density so the tunnel junctions are working in the third quadrant. Ideally, this current density distribution should be emulated in the ALT but by forward biasing, the solar cell in darkness, the current flows in the opposite direction than the photo-generated current density, and the majority of the current flows beneath the busbar and fingers [13]. Therefore, in darkness, the injected current density through the subcells flows in the same direction (negative current) as the recombination current
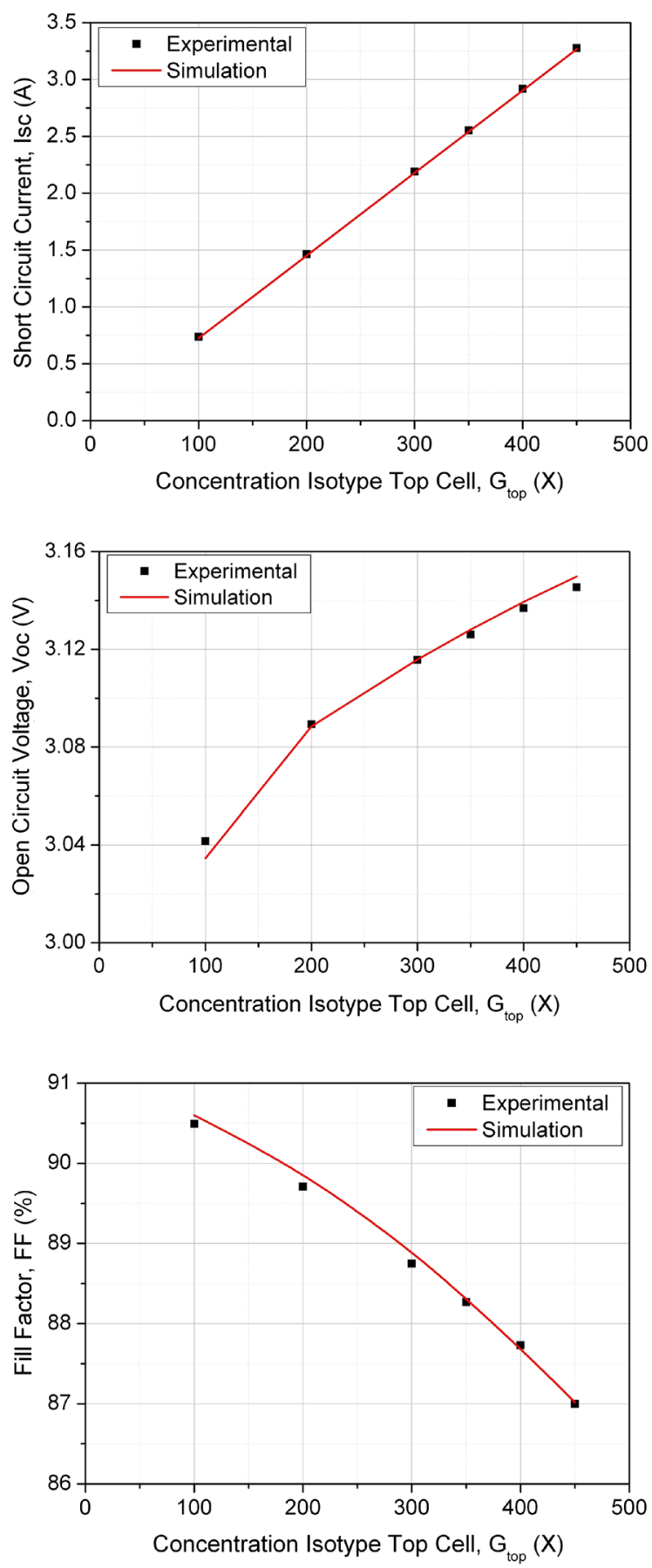

Figure 3. Experimental data and simulation fitting of the main parameters of the illuminated I-V curve of the same triplejunction solar cell presented in Figure 2 under different concentrations detected by the isotype top cell (solar cell with the same spectral response as the top cell in a lattice-matched triplejunction solar cell). See reference [12] for further details in the measurement procedure.

density under illumination. Regarding the tunnel junctions, in darkness, they work throughout the whole solar cell's 
$820 \mathrm{X}$, Maximum power point
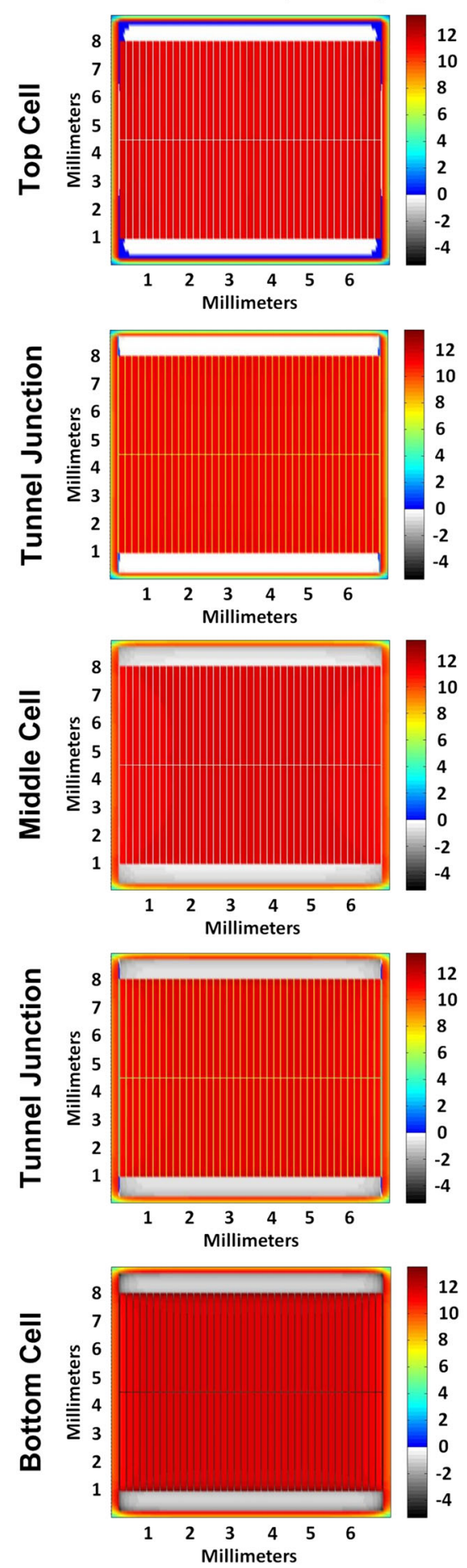

$0 \mathrm{X}, 3.2 \mathrm{~A}$
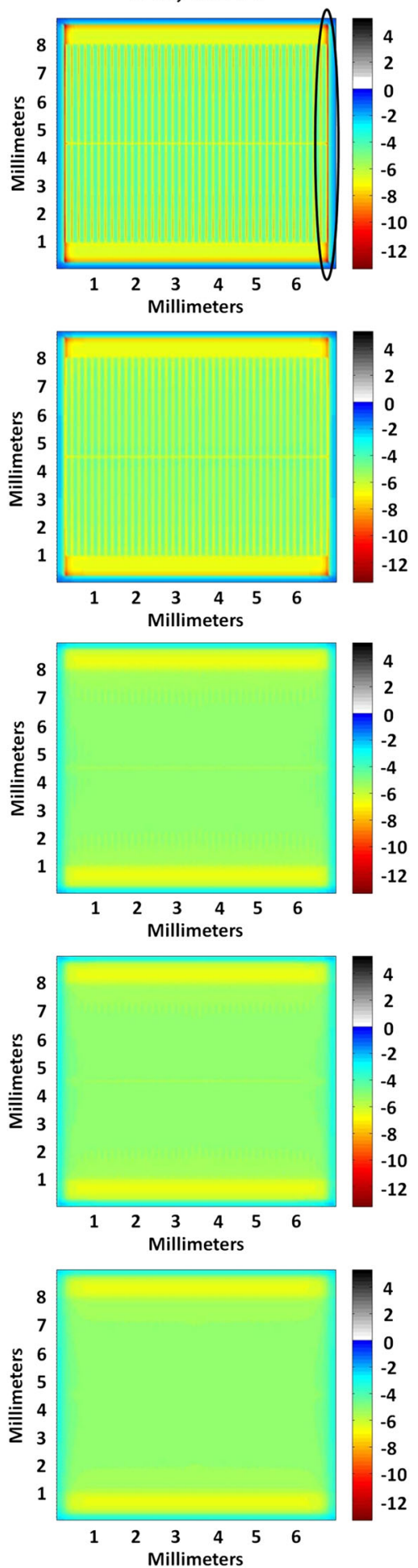

Figure 4. False color maps representing the current density $\left(\mathrm{A} / \mathrm{cm}^{2}\right)$ through the top cell, the top tunnel junction, the middle cell, the bottom tunnel junction, and the bottom cell for an illumination of $820 \mathrm{X}$ at the maximum power point (left figures) and for an injection of 3.2 A in darkness (right figures). The scale of the false color maps is in A/cm ${ }^{2}$. The active area of the solar cell is $0.49 \mathrm{~cm}^{2}$. The black oval in the false color map of the top cell in darkness remarks the external finger which is draining the highest current density. 
area in the third quadrant not only beneath the busbar and fingers as under illumination.

We have used our 3D distributed model to simulate the current density distribution through the pn junctions when different levels of current were injected into the solar cell in darkness. We have simulated different levels of current injected into the solar cell so that the absolute value of the current density distribution in darkness was as close as possible to the current density distribution at 820 $\mathrm{X}$ but without exceeding in darkness the current density photo-generated at $820 \mathrm{X}\left(|11.5| \mathrm{A} / \mathrm{cm}^{2}\right)$ at any point on the solar cell. Therefore, the criterion followed for emulating $820 \mathrm{X}$ is conservative because we have avoided current density over stress. The level of current injection that fulfilled this criterion was 3.20 A. In Figure 4, the current density distribution in darkness through the different junctions when the solar cell is biased with $3.20 \mathrm{~A}$ is shown. At this current, the external fingers in the top cell are draining the highest current density ( about $-11.5 \mathrm{~A} / \mathrm{cm}^{2}$ ). It should be pointed out that we have also qualitatively observed this effect in experimental electroluminescence measurements.

In Table I, we present the equivalent concentrations, which would be needed to photo-generate the current density that each subcell manages in the different regions of the solar cell when $3.2 \mathrm{~A}$ are injected into the solar cells in darkness. Therefore, the emulated condition in darkness in terms of the current density management (in absolute value) is less aggressive than real conditions under $820 \mathrm{X}$.

(iii) The test temperatures.

It has been checked that the solar cell's packaging was able to handle up to $170{ }^{\circ} \mathrm{C}$. Therefore, the maximum solar cell temperature $\left(T_{\text {Solar Cell }}\right)$ of the ALT has been $164 \pm 2{ }^{\circ} \mathrm{C}$. The acceleration factor obtained at $164 \pm 2{ }^{\circ} \mathrm{C}$ was very high because the solar cells failed in a few hours. Therefore, the other two tests were carried out at significantly lower temperatures $119 \pm 2{ }^{\circ} \mathrm{C}$ and $126 \pm 2{ }^{\circ} \mathrm{C}$. These temperatures are high enough to obtain a significant acceleration factor and they are sufficiently separated from each other in order to evaluate accurately the activation energy value. In order to achieve that the solar cells are at these temperatures $\left(T_{\text {Solar Cell }}\right)$ when current is injected through them, the corresponding temperatures of the climatic chambers $\left(T_{\text {Climatic Chamber }}\right)$ have to be calculated because the solar cells will be heated up $(\Delta \mathrm{T})$ by the current injected. In fact, the current which is not recombined radiatively causing the emission of light

Table I. Equivalent concentration needed to photo-generate the same current density as the current density which flows in darkness due to the injection of $3.2 \mathrm{~A}$.

\begin{tabular}{lccc}
\hline Subcell & Busbar & Fingers & Active Area \\
\hline TC & $450 X$ & $470-820 X$ & $250-340 X$ \\
MC & $440 X$ & $320 X$ & $330 X$ \\
BC & $430 X$ & $315 X$ & $320 X$ \\
\hline
\end{tabular}

is transformed into heat. Therefore, the increase in temperature due to the injection of $3.20 \pm 0.01 \mathrm{~A}$ has been calibrated in each climatic chamber. For that, the following steps have been followed:

- The variation of voltage per degree $(\mathrm{dV} / \mathrm{dT})$ has been calculated for each temperature range in each climatic chamber by measuring the voltage at a set current.

- The increase in temperature due to the injection of 3.20 A into the solar cells has been obtained by measuring the variation of the voltage $(\Delta \mathrm{V}$, at the set current in the previous point) immediately after disconnecting the injection of 3.2 A into the solar cell.

- The accuracy in the estimation of the temperature increase due to the current injection has been corroborated by confirming that the voltage measured immediately after the injection of the $3.2 \mathrm{~A}$ was a voltage between the voltages measured when the climatic chamber was five degrees higher and five degrees lower than the expected solar cell's temperature $\left(T_{\text {Solar Cell }}\right)$. Therefore, the maximum error in the estimation of $T_{\text {Solar Cell }}$ is lower than $\pm 5^{\circ} \mathrm{C}$.

It has to be pointed out that several thermocouples were placed inside the climatic chambers to check their temperature spatial uniformity during the tests and it was $\pm 1^{\circ} \mathrm{C}$. Also, the voltage drop in each solar cell during the injection of 3.2 A has been monitored every 10 min during the test. Sudden and/or unexpected variations have not been detected.

(iv) Pre-test solar cell's characterization.

In order to carry out the failure analysis when the tests end, the following characterization techniques have been measured in all the solar cells as follows: $\mathrm{I}-\mathrm{V}$ in darkness, I-V at $1 \mathrm{X}, \mathrm{I}-\mathrm{V}$ at $500 \mathrm{X}$, external quantum efficiency (EQE), electroluminescence mapping, and X-ray transmission imaging.

\section{PROGRESS OF THE TEST}

In the temperature ALT, 45 commercial triple-junction solar cells have been used. They have been divided into three groups, and they have been introduced into three climatic chambers at different temperatures. In order to emulate, working conditions $3.2 \mathrm{~A} \pm 0.01 \mathrm{~A}$ have been injected into the solar cells heating them up to: $119 \pm 2^{\circ} \mathrm{C}, 126 \pm$ $2{ }^{\circ} \mathrm{C}$ and $164 \pm 2{ }^{\circ} \mathrm{C}$. After a period of current injection, all the solar cells were automatically disconnected from the current sources. After a temperature stabilization period, the dark I-V curve of each solar cell has been measured. Once all the solar cells had been measured, the current sources were connected again to the solar cells and the cycle started again. This cycle has been repeated over and over until all the solar cells inside the climatic chambers failed. Figure 5 sketches the temperature cycles of the solar cells inside the climatic chambers. 


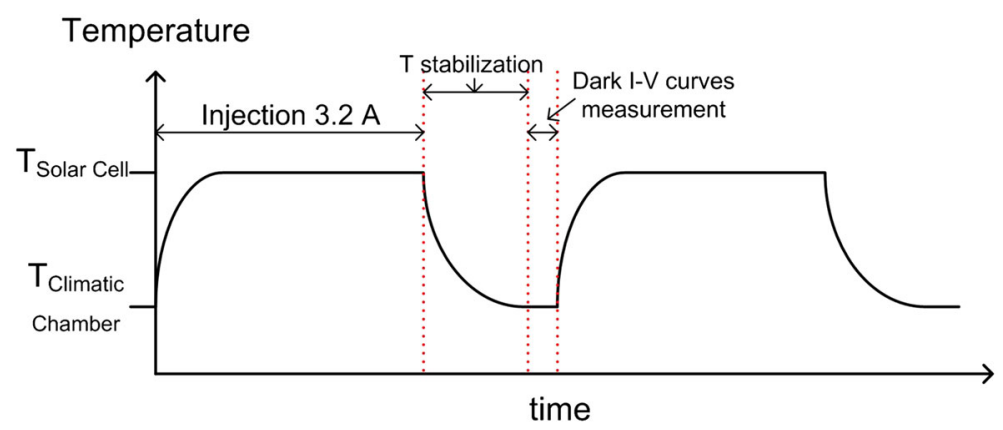

Figure 5. Qualitative sketch of the thermal cycles of the solar cells inside the climatic chamber.

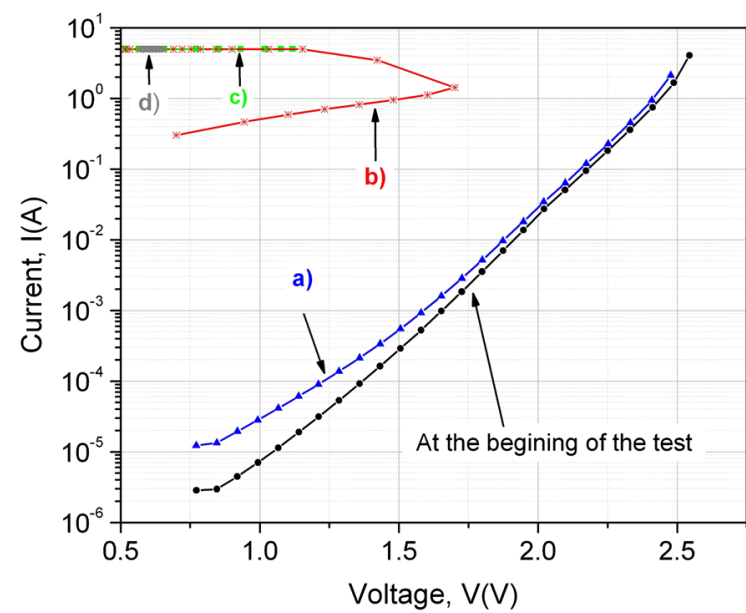

Figure 6. Typical evolution of dark I-V curve (from a to d) of a solar cell tested.

In Figure 6, the typical evolution of the solar cell's dark I-V curve (from a to d) monitored inside the climatic chamber is shown.

Failure is defined as the event, or inoperable state, in which any device does not perform as previously specified [14]. The failure can be (i) catastrophic, when it causes the loss of the device, or (ii) gradual when due to the degradation the device, performance does not meet the specifications. We can see that in the temperature ALT carried out, the solar cells present catastrophic failures because they are drastically broken. In Figure 6, a radical change from stage (a) to (b) is observed and after a few cycles in the thyristor-like curve (stage (b)), the solar cells turned into low resistances (stages (c) and (d) in Figure 6). It has to be pointed out that all the solar cells inside the three climatic chambers have revealed the same catastrophic failure.

\section{RELIABILITY ANALYSIS}

In order to follow the statistical analysis carried out on the temperature ALT in commercial triple-junction solar cells, the main statistical functions and parameters are briefly reviewed in the Appendix section.

\subsection{Procedure}

As it has been previously pointed out in Section 2, once all the solar cells have failed (as shown in Figure 6), the analysis of ALT data starts and consists of the following:

(i) Finding a life distribution model that describes the solar cells failures at different temperatures.

There are many standard statistical distributions that may be used to model the various reliability parameters. However, it has been found that a relatively small number of statistical distributions satisfy most needs in reliability work [14]. In this particular test, we have used the Weibull distribution model because it is a versatile distribution which, by adjustment of the distribution parameters, can be made to model any of the three parts in the typical bathtube curve for a wide range of life distribution characteristics. We have used the Weibull distribution with two parameters $(\beta$ and $\eta)$

$$
f(t)=\frac{\beta}{\eta^{\beta}}(t)^{\beta-1} e^{-\left(\frac{t}{\eta}\right)^{\beta}}
$$

where, $f(t)$ is the failure probability density function, $t$ is the time, $\beta$ is the shape parameter, and $\eta$ is the scale parameter or characteristic life. $\eta$ is defined as the life at which $63.2 \%$ of the population will have failed.

(ii) Finding a life-stress model that quantifies the manner in which the life distribution changes across different temperatures.

The life-stress model that we have used is the wellknown Arrhenius model which is defined with the expression 2 . This model is widely used to predict a semiconductor's life when the acceleration variable is temperature.

$$
L(T)=C \cdot e^{\frac{E_{A}}{k T}}
$$

where $L(T)$ is a temporal measurable characteristic of the life of the device under test which depends on the temperature, $k$ is the Boltzmann constant, $E_{A}$ is the activation energy of the mechanism which causes the failure, and $C$ 
is a parameter of the Arrhenius model which depends on the $L(T)$ used.

(iii) Combining the life distribution and the lifestress model.

The characteristic life of the Weibull model $(\eta)$ has been considered the temporal measurable characteristic of the life of the solar cells under test that depends on the temperature in the Arrhenius model $(L(T))$, and the shape parameter $(\beta)$ has been assumed constant for the three temperatures. Then, the combined Arrhenius-Weibull model, which has been fitted to the experimental data has the expression:

$$
f(t, T)=\frac{\beta}{C \cdot e^{E_{A} / k T}} \cdot\left(\frac{t}{C \cdot e^{E_{A} / k T}}\right)^{\beta-1} \cdot e^{-\left(\frac{t}{C \cdot e^{E_{A} / k T}}\right)^{\beta}}
$$

Therefore, according to Equation A-3 ,the reliability function has the expression:

$$
R(t, T)=e^{-\left(\frac{t}{C \cdot e^{E_{A} / k T}}\right)}
$$

and the instantaneous failure rate (see Equation A-4) has the expression:

$$
h(t)=\frac{\beta}{C \cdot e^{E_{A} / k T}}\left(\frac{t}{C \cdot e^{E_{A} / k T}}\right)^{\beta-1}
$$

(iv) Fitting the Arrhenius-Weibull model to our failure distribution across the different temperatures.

In order to find the parameters of the Arrhenius-Weibull model (expression 3) that are best suited to the set of data obtained in the ALT, the maximum likelihood estimation method (MLE) has been applied and the parameters obtained are as follows:

- $\beta=2.71$

- $C=1.19 \cdot 10^{-17} \mathrm{~h}$

- $E_{A}=1.59 \mathrm{eV}$

A value of the shape parameter $\beta>1$ reveals that the failure rate increases with time (as shown in Figure 12) corresponding with the wear-out failure part of the wellknown bathtube curve commonly used to describe the lifetime of a product.

As far as we know, it is the first time that the Arrhenius activation energy has been obtained for concentrator multijunction solar cells. An activation energy of $1.59 \mathrm{eV}$ seems to be reasonable because typically, the activation energies in III-V optoelectronic devices range from 0.5 to $1.75 \mathrm{eV}$ [15-18].

In Figure 7, the unreliability as a function of time at every stress level used in the test is shown. The experimental data obtained from the ALT (dots) as well as the Arrhenius-Weibull model fitted (lines) are displayed. Figure 7 shows that the model fitted by the MLE estimation method reproduces fairly well the data obtained experimentally in the ALT. Also, the likelihood value obtained $L K=-224$ is satisfactory. Figure 7 also shows the extrapolated line (in black) for unreliability at the specified nominal operation temperature $\left(80^{\circ} \mathrm{C}\right)$.

In Figure 8, the Arrhenius expression is linearized and plotted on a life versus stress plot. The relationship is linearized by taking the natural logarithm of both sides in the Arrhenius equation:

$$
\operatorname{Ln}(\eta(T))=\operatorname{Ln}(C)+\frac{E_{A}}{k T}
$$

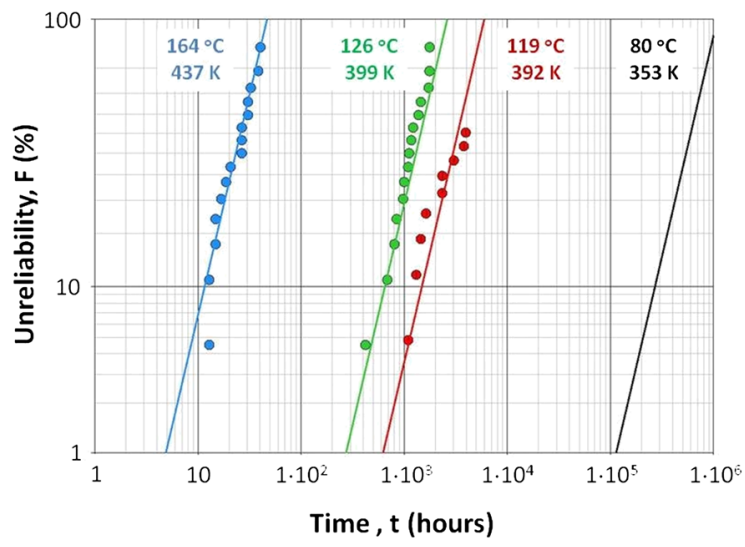

Figure 7. Unreliability as a function of time at every stress level used in the ALT. The experimental data are represented with dots and the Arrhenius-Weibull model fitted for the different test temperatures are represented with a line. The extrapolated line (in black) for unreliability at $80^{\circ} \mathrm{C}$ is also represented.

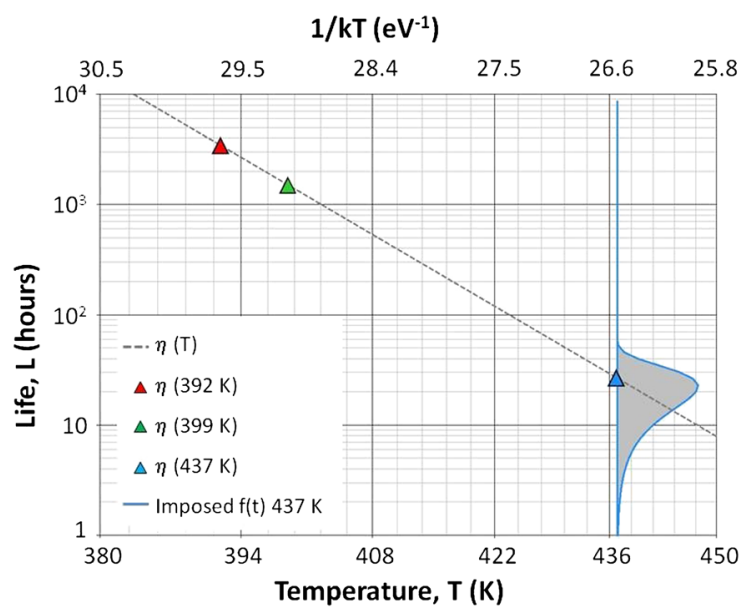

Figure 8. In this figure, the $\eta$ (scale parameter) of the Weibull functions for the different test temperatures are represented (triangles). In the plot, the corresponding failure probability density function $(f(t))$ at $164{ }^{\circ} \mathrm{C}$ is also imposed. Finally, the gray dashed line represents $\eta(T)$ obtained by fitting our failure distributions across the different test temperatures to the Arrhenius-Weibull model. 


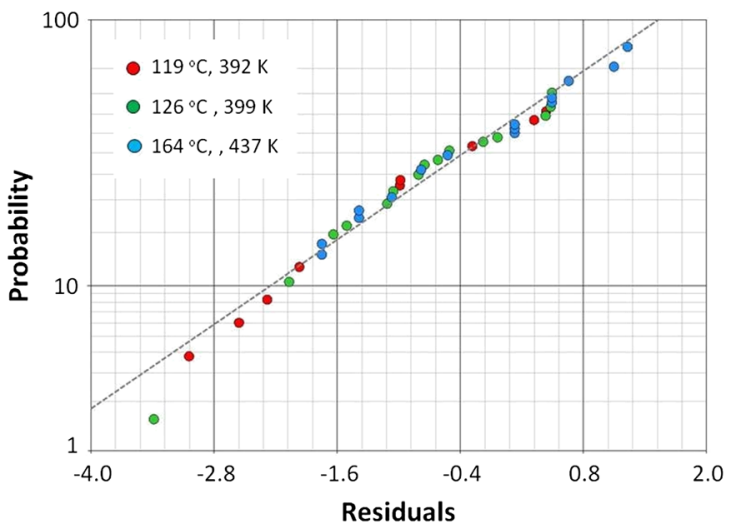

Figure 9. Standardized residuals plot. The residual values for each data point are color coded to indicate which accelerated stress level the associated data point was obtained from.

The parameter $\eta$ of the Weibull functions for the different temperature tests is represented (triangles). For the sake of clarity, the failure probability density functions $(f(t))$ at $164{ }^{\circ} \mathrm{C}$ has also been imposed (shaded area) in the figure. The gray dashed line represents $\eta(\mathrm{T})$, which is the estimated time by which $63.2 \%$ of solar cells in the population are expected to fail if they are working at a nominal temperature $T$.

In Figure 8, we can observe that the $\eta$ parameters of the three test temperatures (triangles) are well- fitted by the Arrhenius-Weibull model used (gray line). Therefore, we can use this life-stress model to extrapolate the behavior of the solar cells tested at the nominal working temperature.

In order to have additional information of the suitability of the model used, we have plotted in Figure 9 the standardized residuals. The residual values for each data point are color coded to indicate from which accelerated stress temperature the associated data point has been obtained, that is, red for the test at $119{ }^{\circ} \mathrm{C}$, green for the test at $126{ }^{\circ} \mathrm{C}$, and blue for the test at $164^{\circ} \mathrm{C}$. Figure 9 confirms that the Arrhenius-Weibull model adequately describes the data because the standardized residuals follow a straight line on the probability plot [19].

\subsection{Reliability extrapolation at nominal working conditions}

Now, we will use the Arrhenius-Weibull model to extrapolate the performance of the solar cells at the nominal temperature of $80^{\circ} \mathrm{C}$ and to determine the influence of the nominal temperature by extrapolating the reliability data also at $100^{\circ} \mathrm{C}$.

The acceleration factor $\left(A_{F}\right)$ is defined as a unitless number that relates the solar cell's life at an accelerated stress level to the life at the nominal stress. It is obtained from the activation energy according to the expression

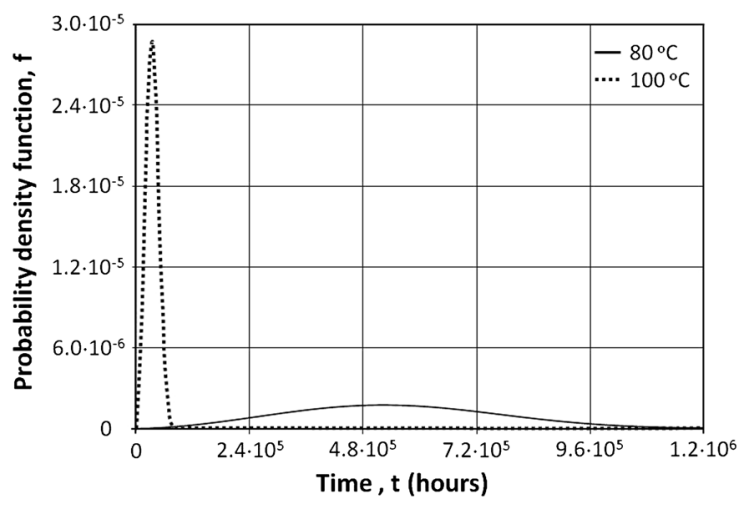

Figure 10. Failure probability density function over time for a nominal working temperature of $80^{\circ} \mathrm{C}$ (solid line) and $100{ }^{\circ} \mathrm{C}$ (dashed line).

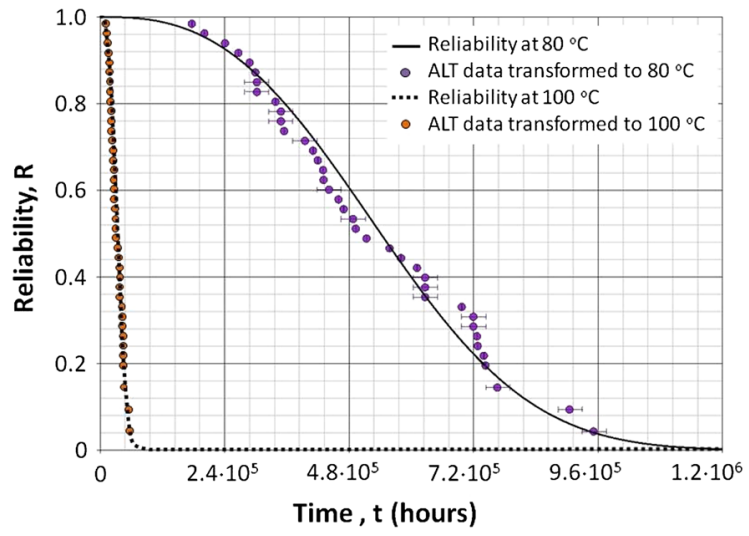

Figure 11. Reliability over time for a nominal working temperature of $80{ }^{\circ} \mathrm{C}$ (solid line) and $100{ }^{\circ} \mathrm{C}$ (dashed line) and the experimental data of the accelerated life tests transformed from the accelerated stress level to the nominal stress level (purple points at $80^{\circ} \mathrm{C}$ and orange points at $100{ }^{\circ} \mathrm{C}$ ) by the corresponding acceleration factor $\left(A_{F}\right)$ obtained

$A_{F}=\frac{\eta\left(T_{\text {Nominal }}\right)}{\eta\left(T_{\text {Stress }}\right)}=\exp \left[\frac{E_{A}}{k}\left(\frac{1}{T_{\text {Nominal }}}\right)-\left(\frac{1}{T_{\text {Stress }}}\right)\right]$

The acceleration factor obtained for the different stress temperatures with respect to the working temperature of $80^{\circ} \mathrm{C}$ has been $A_{F}=182,416$ and 23,252 for the test at $119^{\circ} \mathrm{C}, 126^{\circ} \mathrm{C}$ and $164^{\circ} \mathrm{C}$, respectively.

In Figure 10, the shape of the failure probability density function $(f(t))$ over time (see expression 1 ) at the nominal stresses $\left(80\right.$ and $100{ }^{\circ} \mathrm{C}$ ) can be observed. It is very similar to a normal distribution due to the shape parameter $(\beta=$ 2.71) of the Weibull model.

In Figure 11, the reliability function $(R(t))$ at a nominal temperature of $80^{\circ} \mathrm{C}$ (solid line) and $100{ }^{\circ} \mathrm{C}$ (dashed line) over time is represented. Figure 11 also shows the experimental data of the ALT transformed from the accelerated stress level to the nominal stress level (purple points at $80^{\circ} \mathrm{C}$ and orange points at $100{ }^{\circ} \mathrm{C}$ ) by the corresponding 


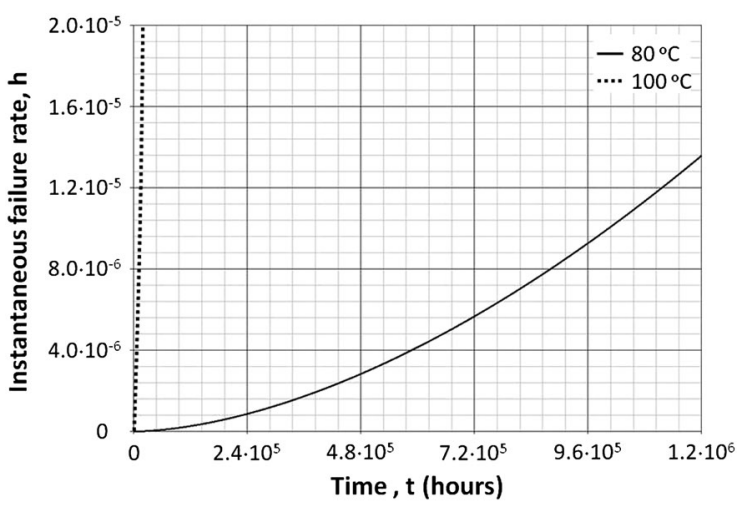

Figure 12. Failure rate function of the triple-junction solar cells for a nominal working temperature of $80{ }^{\circ} \mathrm{C}$ (solid line) and $100{ }^{\circ} \mathrm{C}$ (dashed line).

acceleration factor $\left(A_{F}\right)$ obtained. Good fits between the reliability function extrapolated at nominal working conditions and the transformation of the experimental points are obtained.

In Figure 12, the instantaneous failure rate functions (expression 5) at $80{ }^{\circ} \mathrm{C}$ (solid line) and $100{ }^{\circ} \mathrm{C}$ (dashed line) versus time are shown. The instantaneous failure rate functions monotonically increase corresponding with the wear-out failure part of the well-known bathtube curve.

Finally, by using the Arrhenius-Weibull model, we can have an estimation of the reliability of the concentrator solar cells tested. For that, we have assumed that the solar cells work during their whole life as they do in an average day, that is, $5 \mathrm{~h}$ per day at a concentration of $820 \mathrm{X}$ (conditions emulated in the ALT) and at a temperature of $80{ }^{\circ} \mathrm{C}$. The average day has been defined from the data obtained in Arizona (USA) [20] assuming $1 \mathrm{X}=900 \mathrm{~W} / \mathrm{m}^{2}$ [21]. The reliability parameters obtained are as follows:

- Probability of failure after working 25 years, $F(t=$ $25($ years $))=0.1 \%$.

- Warranty time for a failure population of $5 \%, \mathrm{~W}_{t}(5 \%$ life $)=113$ years.

- Warranty time for a failure population of $10 \%$, $\mathrm{W}_{t}(10 \%$ life $)=148$ years.

- Mean time to failure $(\mathrm{MTTF})=302$ years.

These results are very promising.

If we now assume that the solar cells work at the same concentration $(820 \mathrm{X})$ also during $5 \mathrm{~h}$ /day, but the nominal working temperature is $100{ }^{\circ} \mathrm{C}$ instead of $80^{\circ} \mathrm{C}$, the reliability data obtained are as follows:

- Probability of failure after working 25 years, $F(t=$ 25 (years $))=82 \%$.

- Warranty time for a failure population of $5 \%, \mathrm{~W}_{t}(5 \%$ life) $=7$ years .

- Warranty time for a failure population of $10 \%$, $\mathrm{W}_{t}(10 \%$ life $)=9$ years

- $\mathrm{MTTF}=18$ years.
Therefore, the reliability results are very sensitive to the nominal working temperature.

Finally, several aspects should be taken into account (i) the predictions obtained from the ALT should be confirmed with a standard life test (non-accelerated)-in order to check that the failure mechanism that appears in this ALT is the same as that in real operation under concentration. However, because standard life tests could take several decades until then, ALT is the only tool we have to evaluate the reliability of concentrator solar cells. (ii) In the ALT presented in this work, the acceleration of the aging is due to temperature stress on the solar cells. We need to check if the same failure mechanism is promoted by exposing the solar cells to other stresses such as concentration. (iii) It should be pointed out that each commercial solar cell processing and encapsulation approach could exhibit different failure modes with the subsequent change in their reliability.

\section{SUMMARY AND CONCLUSIONS}

In this paper, a temperature ALT on commercial latticematched $\mathrm{GaInP} / \mathrm{Ga}(\mathrm{In}) \mathrm{As} / \mathrm{Ge}$ triple-junction concentrator solar cells has been carried out. The aging of the solar cells has been accelerated by stressing the solar cells in temperature. The nominal photo-generated current under a concentration of $820 \mathrm{X}$ has been emulated by injecting current in darkness. All the solar cells failures have been catastrophic. The failure distribution across the different temperatures have been fitted to an Arrhenius-Weibull model and its suitability for these solar cells has been verified. We have obtained a shape parameter $\beta=2.71$ and an Arrhenius activation energy $E_{A}=1.59 \mathrm{eV}$, which is compatible with the activation energies obtained in optoelectronic devices. We have used the Arrhenius-Weibull model fitted to extrapolate the main reliability functions (probability density function, reliability, unreliability, and instantaneous failure rate) and parameters (Warranty time, MTTF) to the nominal working conditions. It should be pointed out that the instantaneous failure rate functions (at both nominal working temperatures 80 and $100{ }^{\circ} \mathrm{C}$ ) monotonically increase revealing that the failures are of the wear-out kind. Regarding the warranty time, for a nominal temperature of $80^{\circ} \mathrm{C}$, a long-term warranty could be offered because we have obtained a warranty time for the failure of 5\% of the population of 113 years. However, we have observed that the reliability results are very sensitive to the nominal working temperature. In fact, for a nominal temperature of $100{ }^{\circ} \mathrm{C}$, a long-term warranty could not be offered because we have obtained a warranty time for a failure of $5 \%$ of population of only 7 years. Regarding the MTTF, we have obtained an $(M T T F)=302$ and 18 years for a nominal working temperature of 80 and $100{ }^{\circ} \mathrm{C}$, respectively. As far as we know, this is the first that time that reliability data have been calculated for concentrator multijunction solar cells. Finally, it should be pointed 
out that these results are only applicable in these particular solar cells and with this specific packaging.

\section{ACKNOWLEDGEMENTS}

This work was supported by the European Commission under the project NGCPV 'A new generation of concentrator photovoltaic solar cells, modules and systems' with grant agreement no. 283798. The Spanish Ministerio de Economía y Competitividad has also contributed with the projects TEC2011-28639-C02-01, IPT2011-1441-920000, as well as the Comunidad de Madrid under the NUMANCIA II program (S2009/ENE1477).

\section{REFERENCES}

1. Swanson RM. The promise of concentrators. Progress in Photovoltaics: Research and Applications 2000; 8: $93-111$

2. Luque A, Sala G, Luque-Heredia I. Photovoltaic concentration at the onset of its commercial deployment. Progress in Photovoltaics: Research and Applications 2006; 14(5): 413-428

3. Kurtz S. Opportunities and challenges for development of mature concentrating photovoltaic power industry. Technical Report, National Renewable Energy Laboratory, NREL, 2012.

4. Prior B. Concentrating photovoltaics 2011: technology, costs and markets. Technical Report, GTM Research, 2011.

5. Davies J. The world market for concentrated PV (CPV). Technical Report, IMS Research, 2012.

6. IEC 62108 Ed 1.0: Concentrator photovoltaic (CPV) modules and assemblies - design qualification and type approval 2007.

7. Nelson W. Accelerated testing: statistical models, test plans, and data analysis, Wiley series in probability and mathematical statistics, 2004.

8. Vázquez M, Rey-Stolle I. Photovoltaic module reliability model based on field degradation studies. Progress in Photovoltaics: Research and Applications 2008; 16(5): 419-433, http://dx.doi.org/10.1002/ pip. 825

9. Espinet-González P, Algora C, Orlando V, Núñez N, Vázquez M, Bautista J, Xiugang H, Barrutia L, Rey-Stolle I, Araki K. Preliminary temperature accelerated life test (ALT) on III-V commercial concentrator triple-junction solar cells, In Proceedings of IEEE 38th Photovoltaic Specialist Conference (PVSC), June 3-8, Austin, Texas, USA.

10. Núñez N, González JR, Vázquez M, Algora C, Espinet P. Evaluation of the reliability of high concentrator GaAs solar cells by means of temperature accelerated aging tests. Progress in Photovoltaics: Research and Applications 2012; 21: 1104-1113, http://dx.doi.org/ 10.1002/pip. 2212

11. García I, Espinet-González P, Rey-Stolle I, Algora C. Analysis of chromatic aberration effects in triple-junction solar cells using advanced distributed models. IEEE Journal of Photovoltaics 2011; 1(2): 219-224, DOI: 10.1109/JPHOTOV.2011.2171671

12. Domínguez C, Antón I, Sala G. Multijunction solar cell model for translating I-V characteristics as a function of irradiance, spectrum, and cell temperature. Progress in Photovoltaics: Research and Applications 2010; 18(4): 272-284, DOI: 10.1002/pip.965, http:// dx.doi.org/10.1002/pip.965

13. Galiana B, Algora C, Rey-Stolle I. Explanation for the dark I-V curve of III-V concentrator solar cells. Progress in Photovoltaics 2008; 16(4): 331-338

14. MIL-HDBK-338B: Electronic Reliability Design Handbook.

15. Ueda O. Reliability and Degradation of III-V Optical Devices. Boston: Artech House, 1996.

16. Trevisanello L, Meneghini M, Mura G, Vanzi M, Pavesi M, Meneghesso G, Zanoni E. Accelerated life test of high brightness light emitting diodes. IEEE Transactions on Device and Materials Reliability 2008; 8(2): 304-311

17. González J, Vázquez M, Núñez N, Algora C, ReyStolle I, Galiana B. Reliability analysis of temperature step-stress tests on III-V high concentrator solar cells. Microelectronics Reliability 2009; 49(7): 673-680

18. Christou A, Unger BA. Semiconductor Device Reliability. Kluwer Academic Publishers: Springer, December 1989. ISBN 13: 9780792305361 , ISBN 10: 0792305361.

19. Meeker WQ, Escober LA. Statistical Methods for Reliability Data. Wiley-Interscience: Hoboken, New Jersey, U.S.A., 1998.

20. http://www.nrel.gov/midc/srrl_bms.

21. Muller M. Minimizing variation in outdoor CPV power ratings, In the Photovoltaic Module Reliability Workshop, Golden, Colorado, USA, 16-17 February 2011. Technical Report NREL/TP-5200-60170 November 2013.

22. Kececioglu D. Reliability Engineering Handbook, Vol. 1. DEStech Publications Inc.: Lancaster, Pennsylvania, USA, 2002.

\section{APPENDIX}

The main statistical functions and parameters, used in this paper, are reviewed in this section. 
- The failure probability density function $(f(t))$ is defined as the probability that a device has a failure between the moments $t$ and $t+d t$ (our random variable of interest in life data analysis is time).

$$
\int_{0}^{\infty} f(t) d t=1
$$

- The cumulative distribution function named unreliability $(F(t))$ describes the probability of a failure occurring by time $t$ based on the continuous distribution given by $f(t)$

$$
F(t)=\int_{0}^{t} f(t) d t
$$

- Reliability $(R(t))$ is the probability that a device will perform its design for functions without failure in specified environments for desired periods at a given confidence level [22].

Reliability and unreliability are the probabilities of two mutually exclusive states, and therefore their sum is equal to unity $R(t)+F(t)=1$.

$$
R(t)=1-F(t)=1-\int_{0}^{t} f(t) d t=\int_{t}^{\infty} f(t) d t
$$

where $R(t=0)=1$ and $R(t=\infty)=0$
- The hazard rate, $h(t)$, or instantaneous failure rate, is defined as the limit of the failure rate as the interval length approaches zero

$$
h(t)=\lim _{\left(t_{2}-t_{1}\right) \rightarrow 0}\left[\frac{R\left(t_{1}\right)-R\left(t_{2}\right)}{\left(t_{2}-t_{1}\right) R\left(t_{1}\right)}\right]=\frac{f(t)}{R(t)}
$$

The typical hazard rate in semiconductor devices throughout their entire life is the well-known bathtube curve which comprises three parts

1. The first part with a decreasing failure rate. Failures in this part are named 'infant mortality failures', and they are due to defective items.

2. The second part with a constant failure rate due to random failures during the useful life of the item.

3. The third part with an increasing failure rate. The failures in this regions are known as wearout failures.

- The MTTF describes the expected time to failure for a non-repairable system. It is defined with the expression

$$
M T T F=\int_{0}^{\infty} t \cdot f(t) \cdot d t=\int_{0}^{\infty} R(t) d t
$$

